NISTIR 7231

\title{
Numerical Simulation of the Caldecott Tunnel Fire, April 1982
}

Kevin B. McGrattan 
NISTIR 7231

\section{Numerical Simulation of the Caldecott Tunnel Fire, April 1982}

Kevin B. McGrattan

Fire Research Division

Building and Fire Research Laboratory

December 2005

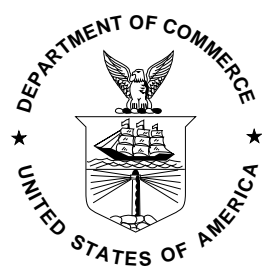

U.S. Department of Commerce Carlos M. Gutierrez, Secretary

National Institute of Standards and Technology William Jeffrey, Director 


\begin{abstract}
This report documents numerical simulations of the thermal environment within the Caldecott Tunnel during a gasoline spill fire in April 1982. A numerical fire model developed by the National Institute of Standards and Technology (NIST) was used to simulate the fire. The model was validated for this application using several data sets from large-scale fire experiments, including fire experiments conducted at a decommissioned highway tunnel in West Virginia, and fire experiments performed as part of the NIST Investigation of the World Trade Center Disaster.

For the Caldecott Tunnel fire, the peak calculated gas temperatures within the tunnel were approximately $1100{ }^{\circ} \mathrm{C}\left(2000{ }^{\circ} \mathrm{F}\right)$, and peak wall surface temperatures were approximately $950{ }^{\circ} \mathrm{C}\left(1750{ }^{\circ} \mathrm{F}\right)$. The peak temperatures were influenced by the net effect of spalling and ablation of the concrete walls and ceiling, and determining the sensitivity of the calculations to this effect was a key objective of the study.
\end{abstract}




\section{Contents}

Abstract

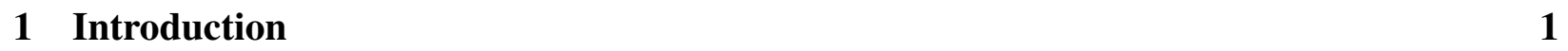

\begin{tabular}{|lll}
\hline 2 & Technical Approach & 2
\end{tabular}

3 Caldecott Tunnel Fire Simulation Parameters 4

3.1 Tunnel Geometry . . . . . . . . . . . . . . . . . . . . . . 4

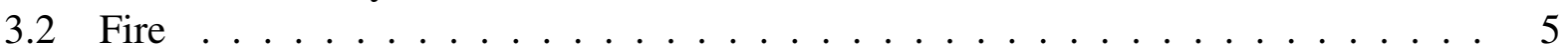

\begin{tabular}{|lr|}
\hline Calculation Results & 6 \\
\hline
\end{tabular}

$\begin{array}{lll}5 & \text { Discussion } & 11\end{array}$

$\begin{array}{lll}6 & \text { Conclusion } & 12\end{array}$

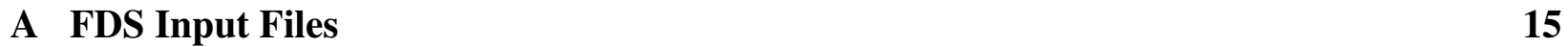




\section{List of Figures}

$1 \quad$ Ablation rate as a function of concrete surface temperature. . . . . . . . . . . . 6

2 Predicted gas temperature time histories at various locations inside the tunnel for simulations with and without the inclusion of concrete ablation. . . . . . . . . 8

3 Predicted surface temperature time histories at various locations inside the tunnel for simulations with and without the inclusion of concrete ablation. . . . . . . . . . 9

4 Predicted gas velocity time histories at various locations inside the tunnel for simulations with and without the inclusion of concrete ablation. . . . . . . . . . 10 


\section{Introduction}

In the early morning of April 7, 1982, a gasoline tanker truck travelling westbound in the No. 3 bore of the Caldecott Tunnel overturned and caught fire as a result of a multi-vehicle accident. The tunnel connects Oakland and Walnut Creek, California. The National Transportation Safety Board (NTSB) and the California Highway Patrol (CHP) conducted investigations of the accident. In addition to a detailed account of the events leading up to the fire, their reports contain information about the tunnel, the damage to the vehicles, walls and fixtures, and various other details [1, 2]. As part of its on-going study of the safety of waste transportation casks, the US Nuclear Regulatory Commission (NRC) requested that the Building and Fire Research Laboratory of the National Institute of Standards and Technology (NIST) perform numerical simulations of the fire to assess the thermal environment within the tunnel. The results of the simulations were used as boundary conditions for a detailed thermo-structural analysis of a transportation cask [3].

The simulations described in this report were not intended to replicate every detail of the fire, since the information about the gasoline spill, tunnel lining materials, etc., was not known to a high enough level of certainty to permit an exact reconstruction of the event. The approach taken was to use what information was known about the incident as a starting point for the calculations, and then to vary the unknown parameters to ascertain the range of possible outcomes.

A similar study to that presented here was conducted by NIST to estimate the thermal environment of the Howard Street Tunnel in Baltimore, Maryland, following the derailment in July 2001 of a freight train and the burning of spilled tripropylene and the contents of surrounding rail cars [4]. The similarities and differences between the Caldecott and Howard Street Tunnel fires are discussed in this report. 


\section{Technical Approach}

In cooperation with the fire protection engineering community, a numerical fire model, Fire Dynamics Simulator (FDS), is being developed at NIST to study fire behavior and to evaluate the performance of fire protection systems in buildings. Version 4 of FDS was publicly released in the summer of 2004. The following is a brief description of the major components of the model. Detailed information regarding the assumptions and governing equations associated with the model is provided in the Technical Reference Guide [5].

Hydrodynamic Model FDS solves numerically a form of the Navier-Stokes equations appropriate for low-speed, thermally-driven flow with an emphasis on smoke and heat transport from fires. The core algorithm is an explicit predictor-corrector scheme, second order accurate in space and time. Turbulence is treated by means of the Smagorinsky form of Large Eddy Simulation (LES). It is possible to perform a Direct Numerical Simulation (DNS) if the underlying numerical grid is fine enough. LES is the default mode of operation.

Combustion Model For most applications, FDS uses a mixture fraction combustion model. The mixture fraction is a conserved scalar quantity that is defined as the fraction of gas at a given point in the flow field that originated as fuel. The model assumes that combustion is mixingcontrolled, and that the reaction of fuel and oxygen is infinitely fast. The mass fractions of all of the major reactants and products can be derived from the mixture fraction by means of "state relations," empirical expressions arrived at by a combination of simplified analysis and measurement.

Radiation Transport Radiative heat transfer is included in the model via the solution of the radiation transport equation for a non-scattering gray gas. In a limited number of cases, a wide band model can be used in place of the gray gas model. The radiation equation is solved using a technique similar to a finite volume method for convective transport, thus the name given to it is the Finite Volume Method (FVM). Using approximately 100 discrete angles, the finite volume solver requires about $15 \%$ of the total CPU time of a calculation, a modest cost given the complexity of radiation heat transfer.

Geometry FDS approximates the governing equations on one or more rectilinear grids. The user prescribes rectangular obstructions that are forced to conform with the underlying grid.

Boundary Conditions All solid surfaces are assigned thermal boundary conditions, plus information about the burning behavior of the material. Usually, material properties are stored in a database and invoked by name. Heat and mass transfer to and from solid surfaces is usually handled with empirical correlations.

The calculations performed for the Caldecott Tunnel fire used a computational grid whose cells were about $0.4 \mathrm{~m}$ near the fire source. A coarse mesh was used farther from the fire, where it was not as important to capture the detailed mixing of fuel and oxygen. The objective of the calculations was to estimate the temperatures within the tunnel and the heat flux to surrounding objects. The ability of the FDS model to accurately predict the temperature and velocity of firedriven gas flows has been previously evaluated by conducting experiments, both lab-scale and full-scale, and measuring quantities of interest. Over the past 3 years, FDS has been used in the 
Federal Building and Fire Safety Investigation of the World Trade Center Disaster. As part of this effort, large scale validation experiments were performed, including fully-engulfing compartment fires [6]. Gas temperatures, heat fluxes, and the major gas species concentrations were predicted by FDS to within $10 \%$ of experimental measurements.

As for tunnel fires, before FDS was used to simulate the Howard Street Tunnel [4], it was validated against measurements made in a decommissioned highway tunnel in West Virginia. For the two full-scale tunnel fire tests that were relevant to the Howard Street Tunnel study, FDS simulations were within $50{ }^{\circ} \mathrm{C}\left(100^{\circ} \mathrm{F}\right)$ of the peak measured values.

FDS can provide valuable insight into how a fire may have developed. The model, however, is only a simulation. The model output is dependent on a variety of input values such as material properties, timelines, geometry, and ventilation openings. Since exact information about the fire site, fuel load, and timeline is never known, estimations are incorporated into the model. Based on experience gained during the Howard Street Tunnel study, the thermal properties of the concrete tunnel walls were identified as the most important in terms of predicted peak temperatures. A parametric study was conducted on the effect of the thermophysical degradation processes (i.e. spalling, decarbonization and ablation) of the concrete lining the tunnel. Details are included in the next section. 


\section{Caldecott Tunnel Fire Simulation Parameters}

The relevant details of the incident that have been used in the present study were included in a report by Tom Shelton for the California Highway Patrol [2], and a report by the National Transportation Safety Board [1]. These reports provided information about the tunnel geometry, fire location and damage. Additional information and insights have been obtained from analyses of the incident by D.W. Larson, R.T. Reese and E.L. Wilmot of Sandia National Laboratories [7], and H. Ingason of SP, Sweden [8].

The simulations of the Caldecott Tunnel fire included only those details that were needed to predict a plausible time history of the tunnel temperatures for a time period of three hours following the ignition of the fire. The simulation was not intended to characterize the smoke concentration or toxicity that might have caused injury or death to the people in the tunnel at that time.

\subsection{Tunnel Geometry}

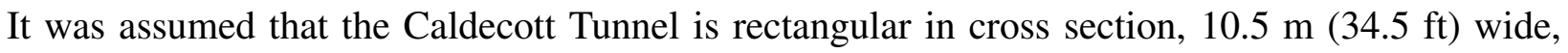
$5.2 \mathrm{~m}(17 \mathrm{ft})$ high, and $1028 \mathrm{~m} \mathrm{(3371} \mathrm{ft)} \mathrm{long.} \mathrm{For} \mathrm{most} \mathrm{of} \mathrm{this} \mathrm{length,} \mathrm{the} \mathrm{tunnel} \mathrm{is} \mathrm{relatively}$ straight with a $4.0 \%$ upgrade from west to east. The upgrade was included in the simulation simply by altering the direction of gravity appropriately. The tunnel was assumed to have been sealed except for the east and west portals. This was a conservative assumption because there was a ventilation system in operation, and this might have allowed heat to escape, lowering near-ceiling temperatures.

The tunnel walls were made of concrete, with an assumed specific heat of $0.88 \mathrm{~kJ} /(\mathrm{kg} \mathrm{K})$, density $2100 \mathrm{~kg} / \mathrm{m}^{3}$ and thermal conductivity $1.4 \mathrm{~W} /(\mathrm{m} \mathrm{K})$ at ambient temperature [9]. No effort was made to model the ceramic tiles or grout, but modifications to the model were made to account for the chemical, thermal and mechanical degradation of the concrete, all of which were accounted for via an assumed "heat of ablation" [10]. The heat of ablation is a term first used by aerospace engineers to describe the degradation of spacecraft re-entering the earth's atmosphere at high speeds. The term has also been used by nuclear engineers in assessing the impact of core meltdown on concrete containment vessels. The heat of ablation is defined as the amount of heat dissipated per unit mass of material undergoing a series of erosion processes resulting in the removal of that mass. It combines the specific heat of the concrete plus the heats of reactions of the various degradation processes. Schneider [10] provides references to various researchers who estimate the heat of ablation for normal concrete to be in a range between $1000 \mathrm{~kJ} / \mathrm{kg}$ to $6000 \mathrm{~kJ} / \mathrm{kg}$ depending on the type of concrete and the method of measurement or analysis. Table 3.1 lists some typical heats of ablation and the temperatures at which concrete undergoes the process.

In FDS, a one-dimensional heat conduction equation for the concrete temperature, $T_{S}(x, t)$, was applied in the direction $x$ pointing into the solid (the point $x=0$ represents the surface)

$$
\rho_{s} c_{s} \frac{\partial T_{s}}{\partial t}=\frac{\partial}{\partial x}\left(k_{s} \frac{\partial T_{s}}{\partial x}\right) \quad ; \quad-k_{s} \frac{\partial T_{s}}{\partial x}(0, t)=\dot{q}_{c}^{\prime \prime}+\dot{q}_{r}^{\prime \prime}-\dot{m}^{\prime \prime} \Delta H_{A}
$$

where $\rho_{s}, c_{s}$ and $k_{s}$ are the density, specific heat and conductivity of the concrete; $\dot{q}_{c}^{\prime \prime}$ is the convective and $\dot{q}_{r}^{\prime \prime}$ is the (net) radiative heat flux at the surface, $\dot{m}^{\prime \prime}$ is the ablation (mass loss) rate and $\Delta H_{A}$ is the heat of ablation. The ablation process was applied at the surface, thus the heat required 
Table 1: Typical values of the heat of ablation of various types of concrete [11].

\begin{tabular}{|l|l|l|}
\hline Concrete Type & Ablation Temperature $\left({ }^{\circ} \mathrm{C}\right)$ & Heat of Ablation $(\mathrm{kJ} / \mathrm{kg})$ \\
\hline \hline Basaltic & $1080-1380$ & $1500-2300$ \\
\hline Limestone Common Sand & $1130-1430$ & $2300-3200$ \\
\hline Limestone & $1230-2280$ & $2900-5100$ \\
\hline Siliceous & $1130-1730$ & $1600-2700$ \\
\hline
\end{tabular}

to liberate mass was essentially extracted from the incoming energy flux. The ablation rate was assumed to be an Arrhenius function of the surface temperature ${ }^{1}$.

$$
\dot{m}^{\prime \prime}=A \rho_{s} e^{-E / T_{s}(0)}
$$

The parameters $A$ and $E$ were chosen to achieve an ablation rate of $0.05 \mathrm{~kg} /\left(\mathrm{m}^{2} \mathrm{~s}\right)$ at a surface temperature of $1000{ }^{\circ} \mathrm{C}$ (see Fig 1). The pre-exponential factor $A$ was chosen to be $0.1 \mathrm{~m} / \mathrm{s}$ so that the mass loss rate would become significant at about $700{ }^{\circ} \mathrm{C}$, the temperature at which decarbonization occurs. The heat of ablation was chosen to be $2400 \mathrm{~kJ} / \mathrm{kg}$.

The chosen values of the parameters related to ablation were based on preliminary calculations in which the relevant parameters were varied to obtain a mass loss rate consistent with observations of "spalling depth" made by Shelton [2]. The term "spalling" is commonly used to describe the physical deterioration of concrete. However, in the analysis to follow, the process of "ablation" included all degradation reactions, such as spalling (which begins near $100{ }^{\circ} \mathrm{C}$, decarbonization (which begins near $700{ }^{\circ} \mathrm{C}$ ), in addition to actual physical ablation of material (which begins near $1000{ }^{\circ} \mathrm{C}$ ). Experience with Eq. (2) as a simple model of pyrolysis has shown that regardless of small changes in the various parameters, the most important parameter is the heat of ablation. Ultimately, the model balances the energy fed back to the surface from the hot gases with the energy consumed in the ablation process and the energy lost due to conduction into the wall. The surface temperature naturally adjusts itself until this balance is achieved.

\subsection{Fire}

As for the fire, Shelton's report to the CHP estimated that 8,600 gal (32 $600 \mathrm{~L})$ of the original 8800 gal (33 $300 \mathrm{~L})$ of gasoline were unaccounted for after the fire and were assumed to have evaporated and/or burned. Experiments performed by Ingason in Sweden [8] suggested that a fire from a leak in the gasoline truck would most likely have melted the upper aluminum lining of the tank, exposing a large pool of gasoline to the increasing heat of the fire. Ingason estimated the pool to have been roughly $30 \mathrm{~m}^{2}$ in area. Larson et al. at Sandia National Labs [7] estimated the burn time to be $40 \mathrm{~min}$. Assuming the gasoline to have a density of $0.75 \mathrm{~kg} / \mathrm{L}$ [9], the evaporation rate would have been about $10 \mathrm{~kg} / \mathrm{s}$. Preliminary simulations of the fire were performed, and none of the results contradicted the cited observations and analyses, except for the fact that in the simulations there was only a brief period of burning at the east portal, even though Shelton's report suggests intermittent flaming for the duration of the fire.

\footnotetext{
${ }^{1}$ This is the same functional form as the solid burning model within FDS. Here, however, the "activation energy," $E$, has been lumped together with the universal gas constant.
} 


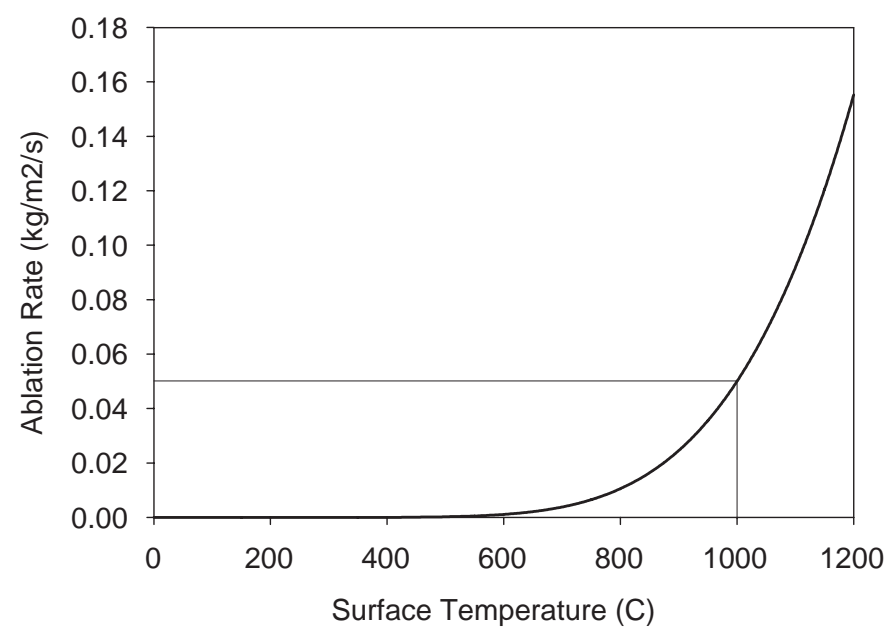

Figure 1: Ablation rate as a function of concrete surface temperature.

\section{Calculation Results}

Simulations of the Caldecott Tunnel fire were performed with various mesh sizes and values of the most important physical parameters. The intent of these preliminary calculations was to assess the sensitivity of the results to each input parameter. Of these calculations, two were chosen and the results were used as boundary conditions for a detailed thermal analysis of a transportation cask [3]. One of the calculations can be described as a "best estimate," that is, the input parameters were chosen based on the information gleaned from the various post-accident reports and the most likely thermo-physical properties of the fuel and concrete. The second calculation was designed to serve as an upper bound in terms of gas and surface temperatures. Specifically, it was assumed that the concrete did not undergo any spalling or ablation. This is not a realistic assumption because the eyewitness accounts described considerable "spalling" throughout large sections of the tunnel. Nevertheless, it was useful to provide a most plausible temperature field, along with an upper bound. Details of the input parameters used in the simulations are given in Appendix A.

Predicted time histories of gas and surface temperatures are provided in Figs. 2 and 3 . The highest gas temperatures were predicted downstream of the fire near the ceiling ("Upper Layer Gas Temperature"), along with the highest surface temperatures ("Ceiling Surface Temperature"). Temperatures at various other locations are included for comparison. Also note the inclusion of the ASTM E 119 and UL 1709 standard time-temperature curves [12, 13]. These temperature curves are used in fire test furnaces to evaluate the performance of building assemblies. The ASTM E 119 curve has been used for over 80 years to characterize typical building fire scenarios. The UL 1709, or "Rapid-Rise" curve, is a more recent addition, meant to characterize a rapidly growing hydrocarbon fuel fire. Obviously, it is more representative of the simulated Caldecott Tunnel fire, but it is not intended to be an upper bound.

Some of the major results of the simulations were:

- Both simulated fires (with and without ablation) induced a $3.3 \mathrm{~m} / \mathrm{s}$ flow from west to east (spatially and temporally averaged). The gases accelerated downstream of the fire due to 
thermal expansion. Predicted time histories of gas velocities at various locations in the tunnel are shown in Fig. 4

- Both fires consumed roughly $70 \%$ of the available oxygen, with a heat release rate of about $400 \mathrm{MW}$. This is probably an over-estimate because the model uses a simple "mixed is burnt" combustion model in combination with an empirical local extinction algorithm. The actual combustion processes are far more complicated and potentially much less efficient in the tunnel environment.

- The maximum ceiling surface temperature was about $950{ }^{\circ} \mathrm{C}$ for the simulation with ablation, and $1100{ }^{\circ} \mathrm{C}$ without ablation.

- The maximum predicted gas temperature near the ceiling was just below $1100{ }^{\circ} \mathrm{C}$ with ablation, and $1150{ }^{\circ} \mathrm{C}$ without. This high temperature region was located roughly $40 \mathrm{~m}$ to $120 \mathrm{~m}$ east of the overturned truck, near the ceiling along the tunnel centerline.

- The simulations predicted that flames exited the east portal, but only for a short time. Shelton's report does not say for how long flames were observed at the east portal. The model probably over-predicted the combustion efficiency of the fire, in which case most of the fuel was consumed somewhere in the tunnel, or never consumed at all. Another possibility was that the observed flaming at the east portal was a result of unsteady evaporation of the gasoline. It was assumed that the gasoline evaporated at a constant rate for $40 \mathrm{~min}$ (about $10 \mathrm{~kg} / \mathrm{s}$ ). However, had there been periods of greater evaporation, this would explain the discrepancy between the observations and the simulation.

Some discussion of maximum temperature is needed. In the numerical model, the gas temperature is literally the temperature of the smoke-laden hot gases, and the surface temperature is literally the temperature of the solid wall at the surface. Shelton's report suggested that the maximum gas temperature could not have exceeded the melting temperature of copper $\left(1065{ }^{\circ} \mathrm{C}\right)$ because copper wiring in the upper wall light fixtures was not melted. Depending on their location relative to the walls/ceiling, the temperature of these wires could have been influenced by both the gas temperature and the nearby surface temperature. The fact that the estimated wire temperature of $1065{ }^{\circ} \mathrm{C}$ was between the predicted peak gas and surface temperatures is consistent with the numerical predictions. It would be difficult to be more precise in this assessment without knowing more details about the exact proximity of the wires to the wall or fixture, and also the extent of conduction of heat along the wire into the wall. 

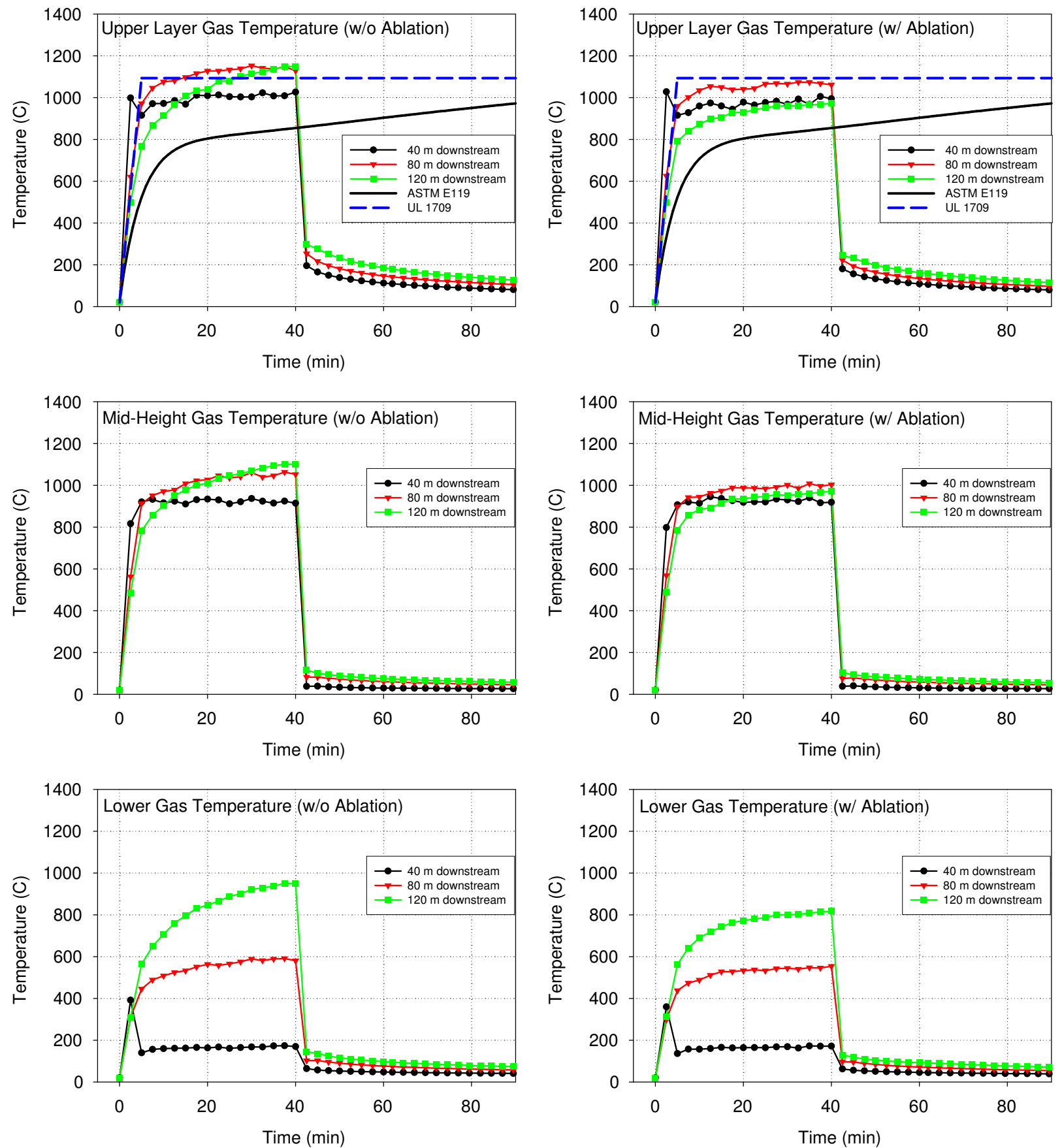

Figure 2: Predicted gas temperature time histories at various locations inside the tunnel for simulations with and without the inclusion of concrete ablation. 

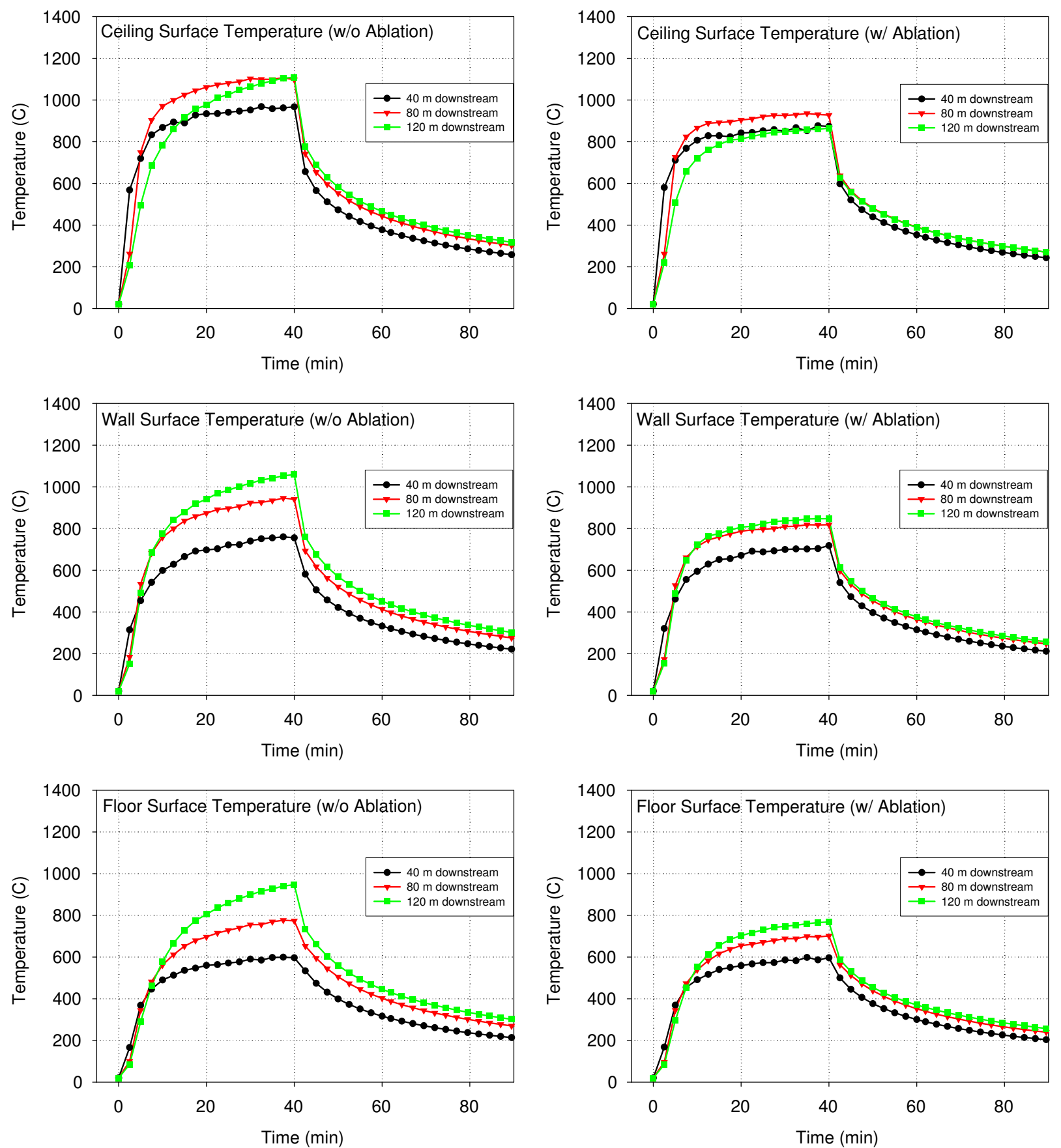

Figure 3: Predicted surface temperature time histories at various locations inside the tunnel for simulations with and without the inclusion of concrete ablation. 

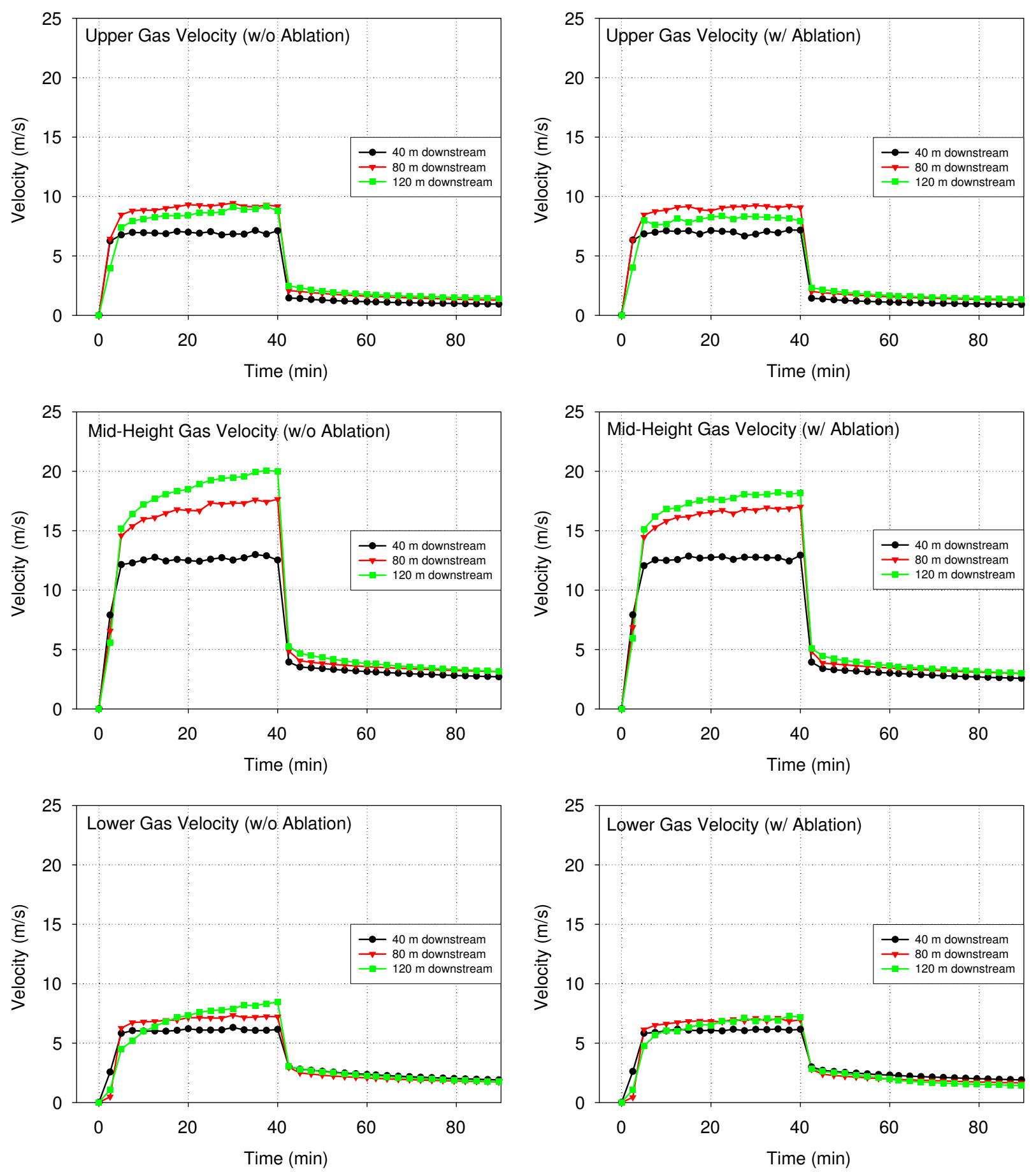

Figure 4: Predicted gas velocity time histories at various locations inside the tunnel for simulations with and without the inclusion of concrete ablation. 


\section{Discussion}

Tunnel fires have been a subject of interest in the fire research community for decades. A common question asked after each fire is: "How hot did it get?" In this report, both numerical modeling and physical evidence have been used to answer that question for the Caldecott Tunnel fire. But what about others? Are there similarities?

Experiments were recently conducted in an abandoned highway tunnel in Norway [14]. The tunnel is $1600 \mathrm{~m}$ long, $6 \mathrm{~m}$ high and $9 \mathrm{~m}$ wide. The fires were located $560 \mathrm{~m}$ from the tunnel exit, and fans were used to create a longitudinal flow of $3 \mathrm{~m} / \mathrm{s}$. In one test, $10900 \mathrm{~kg}$ of wood and plastic pallets fueled a fire whose peak heat release rate was measured to be $200 \mathrm{MW}$ and its peak near-ceiling temperature was $1350{ }^{\circ} \mathrm{C}$. The tunnel geometry and fire location were similar to the Caldecott Tunnel, and the longitudinal flow speed was similar to that predicted by the model. The obvious question to ask is: Why were the predicted temperatures in the Caldecott Tunnel fire $\left(1100{ }^{\circ} \mathrm{C}\right)$ less than those measured in Norway when the tunnel geometry and ventilation conditions were so similar? A possible explanation is the composition of the tunnel walls and ceiling. The Runehamar Tunnel in Norway was lined with a fire-rated insulation material for the fire tests, whereas the Caldecott Tunnel was lined with normal concrete covered with ceramic tile. The severe spalling of the concrete observed by Shelton after the Caldecott fire suggested that the walls could not have sustained the high temperatures measured in the Runehamar fire tests. Spalling and ablation would have continually exposed the fire to cooler surface temperatures.

Next, consider the Howard Street Tunnel fire in Baltimore, July 2001 [4]. Using the same numerical model, the predicted temperatures in the Howard Street Tunnel were less than those predicted in the Caldecott Tunnel. Why? The issue in the Howard Street Tunnel fire was not tunnel lining, but rather, ventilation. The Howard Street Tunnel has a $0.8 \%$ upgrade in the portion of the tunnel where the fire occurred, whereas the Caldecott tunnel has a $4 \%$ upgrade where the fire occurred. The longitudinal flow in the Caldecott tunnel fire was one-directional, as evidenced by the lack of observed sooting on the walls downhill of the fire. During the Howard Street fire, smoke was observed pouring out of both portals. In the simulations of the Howard Street fire, the make-up air from both portals mixed with combustion products so that the air reaching the fire had a reduced oxygen concentration. It is difficult to simulate exactly the combustion processes in such an under-ventilated fire, but it is clear that the fire would not have been able to grow to a size that was measured in Runehamar (200 MW), and estimated in Caldecott (300 MW to $400 \mathrm{MW}$ ), both of which had one-directional flow.

The two most important factors in a tunnel fire are ventilation and lining material. Fuel load, so long as it is plentiful, is not a limiting factor on temperature, although it will certainly limit duration. The highest temperatures are achieved in fires with adequate ventilation and well-insulated walls. The Runehamar experiments had both of these elements, plus truck-loads of combustibles. The Caldecott Tunnel fire had substantial ventilation because of its $4 \%$ slope, but its walls were made of normal concrete and could not withstand temperatures much beyond $1000{ }^{\circ} \mathrm{C}$. Finally, the Howard Street Tunnel fire had neither good ventilation nor "good" wall materials, and consequently exhibited the lowest temperatures of the three fires, at least according to the numerical analyses. 


\section{Conclusion}

The Caldecott Tunnel fire of April, 1982, was modeled using the Fire Dynamics Simulator, a computational fluid dynamics fire model developed by the National Institute of Standards and Technology. The objective of the calculations was to quantify the peak gas and surface temperatures that were likely reached during the roughly $40 \mathrm{~min}$ burn and the cool down period afterwards.

The peak calculated gas temperatures were approximately $1100{ }^{\circ} \mathrm{C}$ and the peak wall surface temperatures were about $950{ }^{\circ} \mathrm{C}$. These temperatures were consistent with physical evidence collected at the scene, especially copper wiring in the light fixtures that approached, but did not reach the melting temperature of $1065{ }^{\circ} \mathrm{C}$. It has been assumed that objects near the wall would have exhibited temperatures between the peak gas and surface values.

A sensitivity study was undertaken to ensure that variations in the physical parameters of the model and the accident scenario would not lead to dramatic changes in the overall results. As a check on the uncertainty in the parameters governing the ablation process, a calculation was performed in which the concrete was not assumed to spall or ablate. The results of this calculation served as an upper bound on the estimated peak gas and surface temperatures. 


\section{References}

[1] Multiple Vehicle Collisions and Fire - Caldecott Tunnel near Oakland, California, April 7, 1982. Highway Accident Report, Adopted: May 3 1983. NTSB Case Reference Number: HAR-83/01; NTIS Number PB83-916201.

[2] T. Shelton. California Highway Patrol (CHP) Multidisciplinary Accident Investigation Team (MAIT) Report Documenting the Caldecott Tunnel Disaster of April 7, 1982. NCIC 9370, April 1982.

[3] B.J. Koeppel, J.M. Cuta, and H.E. Adkins. Spent Fuel Transportation Cask Response to the Caldecott Tunnel Fire Scenario. Report PNNL-15346, Pacific Northwest National Laboratory, Richland, Washington, 2006. US Nuclear Regulatory Agency, Washington DC, NUREG/CR-6894.

[4] K. B. McGrattan and A. Hamins. Numerical Simulation of the Howard Street Tunnel Fire, Baltimore, Maryland, July 2001. NISTIR 6902, National Institute of Standards and Technology, Gaithersburg, Maryland, January 2003. Joint Publication of NIST and the US Nuclear Regulatory Commission (NUREG/CR-6793).

[5] K.B. McGrattan (editor). Fire Dynamics Simulator (Version 4), Technical Reference Guide. NIST Special Publication 1018, National Institute of Standards and Technology, Gaithersburg, Maryland, July 2004.

[6] K. McGrattan, C. Bouldin, and G. Forney. Federal Building and Fire Safety Investigation of the World Trade Center Disaster: Computer Simulation of the Fires in the WTC Towers. NIST NCSTAR 1-5F, National Institute of Standards and Technology, Gaithersburg, Maryland, September 2005.

[7] D.W. Larson, R.T. Reese, and E.L. Wilmot. The Caldecott Tunnel Fire Thermal Environments, Regulatory Considerations and Probabilities. Internal Report to US Department of Energy under contract number DE-AC04-76DP00789, Sandia National Laboratories, Albuquerque, New Mexico, 1984.

[8] H. Ingason. Small Scale Test of a Road Tanker Fire. In Proceedings of the International Conference on Fires in Tunnels, Boras, Sweden, October 10-11, 1994, pages 238-248, 1994. SP Swedish National Testing and Research Institute, Fire Technology, SP Report 1994:54. Distributed by Interscience Communication Limited, London.

[9] J.G. Quintiere. Principles of Fire Behavior. Delmar Publishers, Albany, New York, 1998.

[10] U. Schneider. The Behavior of Concrete at High Temperature. Institute for Building Materials, Building Physics and Fire Protection, Vol. 9, Vienna University of Technology, Vienna, Austria, 2000.

[11] V. Strizhov. An Assessment of the CORCON-Mod3 Code. Technical Report NUREG/IA0129, US Nuclear Regulatory Commission, September 1996. 
[12] American Society for Testing and Materials, West Conshohocken, Pennsylvania. ASTM E 119, Standard Test Methods for Fire Tests of Building Construction and Materials, 2002.

[13] Underwriters Laboratories, Northbrook, Illinois. UL 1709, Standard for Rapid-Rise Fire Tests of Protection Materials for Structural Steel, 1994.

[14] A. Lonnermark and H. Ingason. Fires in Heavy Goods Vehicle (HGV) Cargos in Tunnels. In Proceedings of the Tenth International Interflam Conference, pages 1529-1540. Interscience Communications, London, 2004.

[15] K.B. McGrattan and G.P. Forney. Fire Dynamics Simulator (Version 4), User's Guide. NIST Special Publication 1019, National Institute of Standards and Technology, Gaithersburg, Maryland, July 2004. 


\section{A FDS Input Files}

Below is a print-out of the electronic file containing the parameters used by FDS to simulate the Caldecott Tunnel Fire. The version of FDS used in the study was 4.05 (February 2005). Details can be found in Ref. [15].

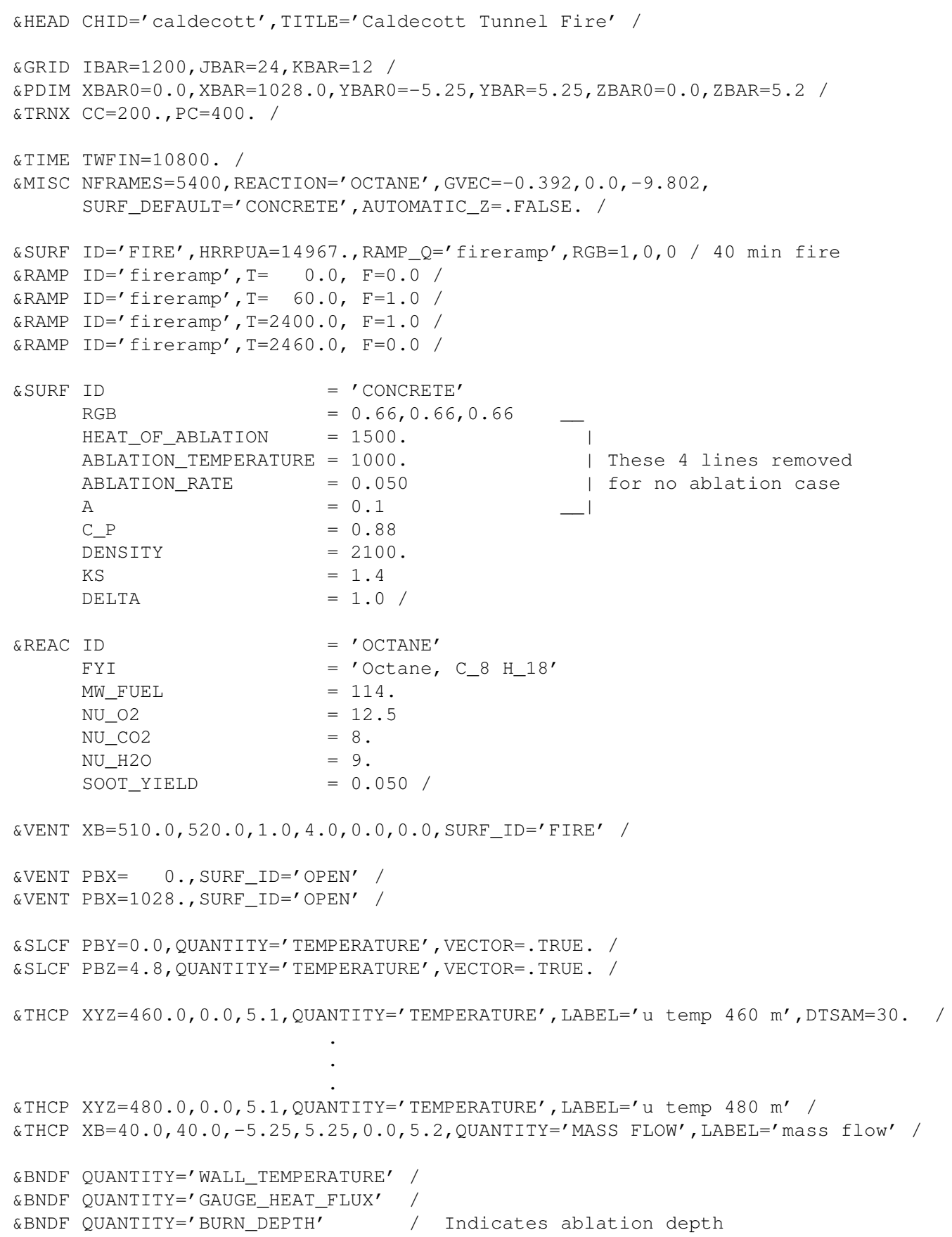


A few technical notes:

- The parameter AUTOMATIC_Z=.FALSE . instructs the program not to make any adjustment to the basic mixture fraction combustion model. There are scenarios in which the fire is small and/or the numerical mesh is coarse, where the stoichiometric flame surface needs to be rescaled. No such adjustment was needed for the Caldecott Tunnel simulations and the feature was turned off.

- The parameter NFRAMES controls the number of times that output data will be dumped during the calculation.

- The $4 \%$ grade of the tunnel was simulated by rotating the direction of gravity $\tan ^{-1}(0.04)=$ $2.3^{\circ}$. The new gravity vector was $-9.81\left(\sin 2.3^{\circ}, 0, \cos 2.3^{\circ}\right)$.

- The ablation rate was governed by the expression

$$
\dot{m}^{\prime \prime}=A \rho_{s} e^{-E / T_{s}}
$$

The parameters ABLATION_RATE $\left(\dot{m}^{\prime \prime}\right.$ in $\mathrm{kg} /\left(\mathrm{m}^{2} \mathrm{~s}\right)$, ABLATION_TEMPERATURE ( $T_{s}$ in $\left.{ }^{\circ} \mathrm{C}\right)$, DENSITY $\left(\rho_{s}\right.$ in $\left.\mathrm{kg} / \mathrm{m}^{3}\right)$, and A $(\mathrm{m} / \mathrm{s})$ on the CONCRETE SURF line were used to compute the remaining parameter $E$. This procedure established the functional dependence between the concrete surface temperature and the ablation rate. The parameter HEAT_OF_ABLATION $(\mathrm{kJ} / \mathrm{kg})$ defined the energy loss per unit mass ablated. Removing all parameters associated with the ablation process effectively eliminated the ablation process altogether for the upper bound simulation.

- The HEAT_OF_ABLATION was set to $1500 \mathrm{~kJ} / \mathrm{kg}$ in the model. This value did not include the energy required to bring the concrete to the ABLATION_TEMPERATURE. The literature values for the heat of ablation given in Table 3.1 include the sensible enthalpy $c_{s} \Delta T$. For concrete at $1000{ }^{\circ} \mathrm{C}, c_{s} \Delta T \approx 900 \mathrm{~kJ} / \mathrm{kg}$.

- The RAMP lines dictated that the fire should grow to $450 \mathrm{MW}$ (area of FIRE $\times$ HRRPUA) in $60 \mathrm{~s}$, burn for $40 \mathrm{~min}$, then extinguish due to lack of fuel. Actually, FDS set an evaporation rate that would ideally produce $450 \mathrm{MW}$, but the computed heat release rate was less (400 MW) because of the limited ventilation.

- The SOOT_YIELD was difficult to determine for the fuel and the fire scenario. A few test calculations indicated that the results were not appreciably sensitive to its value. Also, experiments performed as part of the NIST World Trade Center Investigation indicated that the temperature, rather than the soot volume fraction, of the hot gas layer plays a greater role in determining the heat flux to neighboring objects [6].

- Several hundred virtual "thermocouples" were prescribed in the input file to record the time histories of gas and surface quantities at various locations. These have been omitted for brevity. 